\title{
Retronyms in uzbek language
}

Dr.Sc. Marufjon Yuldashev ${ }^{I}$

${ }^{1}$ Uzbek Institute of Arts and Culture Department of "Uzbek language and literature"

Email:marufcany@gmail.com

\begin{abstract}
The term retronym was first used by the American journalist Frank Mankievich. William Sapphire made the term popular through an article he wrote for the New York Times. The term was included in the interactive edition of the American Heritage Dictionary, an interactive edition, with the following comment: For example, an acoustic guitar against an electric guitar or an analog clock against an electronic clock. "A retronym is a name derived from the first form of a concept or object. In other words, it represents a new word or phrase that has been devised to distinguish it from its related species. Major changes in the political, economic, scientific and cultural life of the country allow to increase the number of terms in the Uzbek language. This process is widely observed in all styles of literary language, especially in the scientific style and the journalistic style. Collecting them and defining their place in the lexicon is one of the current problems facing our linguistics. The article discusses retronyms and their differences from other phenomena and their place in lexicography.
\end{abstract}

Keywords: retronym, retronymic unit, term, neologism, lexicography.

\section{INTRODUCTION}

Linguist Wilhelm von Humboldt (Wilhelm von Humboldt 1767-1835), speaking of the regular growthchange feature of language, pointed out that language was not created as a result of a work or any other activity, but as an activity constantly evolving: "Language is not a product of activity (ergon), but activity itself (energeia)." (Feshchenko: 2012, 87.) If language were a work, it would not change after creation, it would remain as it was created. Whereas language has the power to grow and change, to renew itself regularly. It has been living in the shadow of power for a long time in any situation. Different eras, in spite of different approaches, the language has adapted to innovations without losing its original essence. So language is a phenomenon that can adapt to any situation. The implication is that the viability of language is not limited to "energy." Regular activity "energy" itself does not fully reflect the viability of language. In our view, the viability feature of language is related to its flexibility phenomenon. It is safe to say that this feature of language is associated with its "owner". Because since the beginning of a process called life on our planet, so many creatures in motion have appeared and disappeared. Man, on the other hand, continues to adapt to different climatic conditions and natural phenomena. It is natural that this flexibility in a person is "transmitted" to his tongue. Humboldt emphasizes the need to focus on language as the spirit of the people: "in every language it reflects the spirit of the speakers, the spirit of each nation is reflected in the language." (Lobanova: 2013, 5.) It is known that in world linguistics the role of a certain nation in the description of the linguistic landscape of the world, how it is expressed through language, different national and cultural views, unique way of thinking, as well as language. The study of general and specific aspects of the existing worldview has become one of the most pressing issues. "As a result of the emergence and stabilization of a new scientific paradigm based on the principle of anthropocentric approach to language in linguistics, researchers fully recognize that the essence of language and the human factor should be the main criterion in the scientific interpretation of related events. Objective conclusions can only be drawn when the language is studied together with its owner. " (Mahmudov, Adilov: 2014, 3) In recent decades, the study of language in Uzbek linguistics, along with its owner, its national culture, worldview and other peculiarities, has become a key principle.

\section{THE PURPOSE AND OBJECTIVES OF THE WORK}

It occurs in a round when a concept or object emerges. In other words, no diversity is observed. Over time, in particular, depending on technical, scientific, or cultural developments, "diversity" may disappear and be replaced by diversity. (Yellow: 2013, 22.) For example, when first manufactured, watches were of a nonanalog type. As a result of technical advances, the types of watches have also increased. Wristwatch, desk watch, floor watch, pendant watch, pocket watch; metal watch, plastic watch; stopwatch, electromechanical clock, etc. In the 19th century, a wristwatch was invented to be worn by hand, and this type was called a 
wristwatch. When the electric clock was invented in Russia in 1840, the name of this new type was also called the electric clock. By the 20th century, electromechanical, electroquartz, molecular, and atomic clocks were produced. Their names came to be called accordingly. Built in 1947, the Tashkent clock tower is equipped with 4 dial rusted electric clocks. "According to their function, watches can be conditionally divided into household and special types. Home watches: women's and men's watches, pocket watches, alarm clocks. (alarm clock), table clock, hanging clock, floor clock. Special clocks: chess clock, stopwatch, chronoscope, etc. According to the energy source, atomic, quartz, mechanical, molecular and electrical; According to the vibration system, it is divided into pendulum, balanced and tuning fork. "(UzME. "Hour" article)

A radio-electronic device designed to receive, amplify, and convert electrical signals (telesignals) of television broadcasts from a television studio was originally called a television. White TV. Color TV. LSD TV.

\section{MAIN PART}

Electrocoustic device for subscribers to talk; the last subscriber device of telephone networks, the first transmitter-receiver device used in practice was invented in 1876 by the Scottish inventor A. G. Bell invented. Later, inventors and scientists from different countries perfected it. The telephone consists of a talking part (telephone and microphone, which are connected to a common body, ie a tube), a part that calls the subscriber (disk or keypad, ie a signal bell) and a switching device (connects the part of the device to the talking part). As a result of the structural and functional improvement of the telephone apparatus, new units - retronyms appeared in the language, such as telephone - video phone - mobile phone - smartphone.

The term retronym was first used by the American journalist Frank Mankievich. William Sapphire made the term popular through an article he wrote for the New York Times. The term was included in the interactive edition of the American Heritage Dictionary, an interactive edition, with the following comment: For example, an acoustic guitar against an electric guitar or an analog watch against an electronic clock. "1

Retronym (Lat. Retronym <lat. Retr (o) - "back" + ing. -Onym "horse, word") is a name for an independent concept or the first form of an object to express this variety. Represents a new word or phrase that has been devised to distinguish it from its related species. (Denham and Lobeck 2012: 305).

Russian linguist A.B. Antonova also explains the term in her article on the Russian retronymic layer as follows: predmeta ili dlya sovokupnosti novogo predmeta i ranee sushchestvovavshego [3]. The term was first recorded in 2000. v The American Heritage Dictionary (4th edition). Yavlenie retronimii v dannom znachenii yavlyaetsya eshche nedostatochno razrabotannim v otechestvennoy lexikologii. ${ }^{2}$

K. In his dissertation, Mkhitaryan concludes that retronymy stems from the tendency to differentiate as one of the ways to reconsider the existing reality. Retronymy is associated with the need to give each species a specific name and thus establish a logical gender-species relationship. Most retronyms reflect the narrowing of meaning that results from the expansion of the meaning of a word that originally signifies this or that reality.

When a product is manufactured, it differs from the previous ones in terms of the method or form of processing. It becomes necessary to distinguish between old and new. The retron of the word television is black and white television, color television and others.

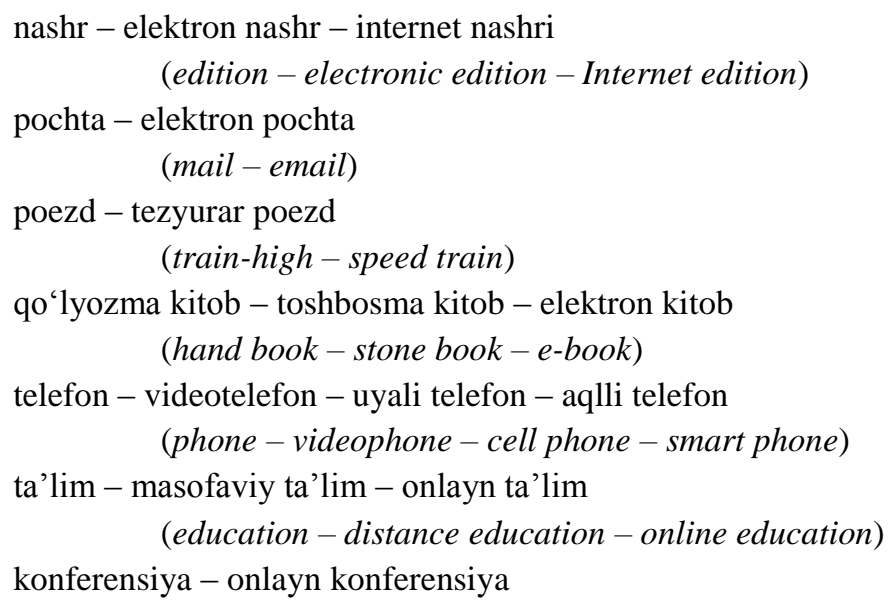

\footnotetext{
${ }^{1}$ http://www.yourdictionary.com/retronym\#americanheritage

2 Antonova A.B. The phenomenon of retronymia in modern Russian. "Magister Dixit" is a scientific and pedagogical journal of Eastern Siberia. No. 1 (17). April 2015
} 
(conference - online conference)

shahar - aqlli (smart) shahar

(city - smart city)

iqtisodiyot - raqamli iqtisodiyot

(economy - digital economy)

choynak - elektrli (elektrikli, elektrik, elektr) choynak

(kettle-electric kettle)

qozon - elektrli (elektrikli, elektrik, elektr) qozon

(boiler-electric boiler)

soch - taqma soch, ulama soch

(hair-tie hair)

kiprik - taqma kiprik, yasama kiprik

(eyelash - tie eyelash, legislative eyelash)

teri - sun'iy teri - oshlangan teri

(skin-artificial leather-pickled skin)

efir - jonli efir

(efir - live efir)

ijro - jonli ijro

(performance - live performance)

kontsert - jonli kontsert - onlayn kontsert

(concert-live concert-online concert)

musiqa - jonli musiqa

(music-live music)

gul - sun'iy gul

(flower-artificial flower)

printer - lazer printer - 3D printer

(printer-laser printer $-3 D$ printer)

film - HD film - 3D film

(movie - HD movie - 3D movie)

dars - onlayn dars

(lesson - online lesson)

kurs - onlayn kurs

(course-online course)

An online publication reported: "Clothing manufacturer Ralph Lauren is working with OMsignal to launch PoloTech smart T-shirts." As it is understood from the report, retronymic relations have started to appear in the clothing industry as a result of technical progress. T-shirt - smart t-shirt.

The Covid-19 pandemic, which has caused great concern around the world, is also expanding the fund of retronyms in national languages. "100 million copies of the new coronavirus will make room for a sharpedged needle." (From the newspaper) The term "new coronavirus" in this text is actually a retronym for "coronavirus." However, it is still understood as a "emerging coronavirus" because it has not yet been identified at the retronym level. That is, the term "new coronavirus" still belongs to the neological layer.

It should be noted that retronyms should be distinguished from neologisms. In neologisms, the color of novelty is clearly felt. While retronyms are relatively new to the origin, they are stagnant and have lost the color of novelty. For example, the word electric car is derived from the electric vehicle retron, but the word has not yet been recognized as the name of a new species. Therefore, the electric car is currently a unit of neological layer. Similarly, a mask - a medical mask - is a "smart mask"; the new units involved in the maskmedical mask-smart mask paradigm are neologisms. Recently, in connection with the pandemic, new words and terms have been introduced into the world's languages. Some peoples are trying to adapt such words and terms to their language. For example, in Turkish, the word pandemic is replaced by the word pandemic, and the word infection is replaced by infection, and the word epidemic is replaced by the word epidemic. and the words entube (entube) and solunum (solunum) instead of the word salgin (salgin), filiation (filiation) and turevsal (derivative) instead of the word filiation are used in parallel instead of the word isolation (insulation) and yalitim (insulation). It seems that Turkish terms alternative to international medical terms are also becoming more active in consumption. There are some attempts in the Uzbek language in this regard. For example, words such as isolation, isolation are suggested as an alternative to the term isolation. The term social 
distancing in English came into the language as social distance and has become somewhat popular. It should be noted at this point that the controversy surrounding the concept of social distance has yet to be transferred to other languages in this way without a clear solution in English itself. The English term social distance was used to refer to the distance between social strata and groups, and began to be used to refer to the distance that must be maintained between people in connection with a pandemic.

Linguistic retronyms allow thematic classification: toponyms, anthroponyms, names of historical events (World War I - World War II), object names (clock - analog clock, acoustic guitar - electric guitar), process names (education - distance education), etc.

\section{CONCLUSION}

The great changes taking place in the political, economic, scientific and cultural life of the country allow for the increase and improvement of terms in the dictionary of the modern Uzbek language. This process is widely observed in all styles of literary language, especially in the scientific style and the journalistic style. Collecting them and defining their place in the lexicon is one of the current problems facing our linguistics. It is necessary to determine the place of retronyms in the dictionary. When adding retronyms to the dictionary, it is advisable to give them in the form of a sub-article within the relevant word article. For example: clockrelated retronyms can be given under the clock lexeme.

\section{REFERENCES}

[1] Lobanova L.P. The concept of a linguistic picture of the world and its origins in the writings of Wilhelm von Humboldt. - M .: APK and PPRO, 2013 .- 408 p.

[2] Lobanova L.P. Language as an energy concept in c. Von Humboldt and L. Weisgerber. Electronic scientific journal "World of Linguistics and Communication" 2013. No 3 (32)

[3] Mahmudov N., Odilov Yo. Contradiction in the development of word meaning. Annotated dictionary of enantiosemic words of Uzbek language. -Tashkent: Akademnashr, 2014. -288 p.

[4] Mahmudov N., Khudoyberganova D. Annotated dictionary of Uzbek language analogies. Tashkent: Manaviyat, 2013. -320 p.

[5] Feshchenko V.V. Language as Creativity and Creativity in Language: Towards the History of a Linguistic Idea. Criticism and semiotics. Vol. 17, 2012. S. 87 (84-94.)

[6] Sarı İ. Dilde Yeniden Adlandirma İhtiyaci: Retronimler. Türkbilig, 2013/25: 19-26.

[7] Antonova A.B. The phenomenon of retronymia in modern Russian. "Magister Dixit" is a scientific and pedagogical journal of Eastern Siberia. No. 1 (17). April 2015

[8] Mkhitaryan K. Modern passports of the development of the English language and the factor of retronymia in modeling the linguistic picture of the world: dis. ... Doctor of Philology: 02.10.04.Batumi.

[9] Yuldashev M. Synonymic Words in AbdulhamidSulaymonCho'lpon's Works. The International journal of analytical and experimental modal analysis. ISSN No:0886-9367. Volume XII, Issue VI, June/2020. PageNo: 1732-1739.

[10] Irgashevich, D. A. (2020). Development of national network (tas-ix). ACADEMICIA: An International Multidisciplinary Research Journal, 10(5), 144-151. Article http://dx.doi.org/10.5958/2249$\underline{7137.2020 .00254 .2}$ 